\title{
Philosophiques
}

\section{Sélection des ouvrages reçus}

\section{Marc-Antoine Dilhac}

Volume 41, numéro 1, printemps 2014

URI : https://id.erudit.org/iderudit/1025736ar

DOI : https://doi.org/10.7202/1025736ar

Aller au sommaire du numéro

Éditeur(s)

Société de philosophie du Québec

ISSN

0316-2923 (imprimé)

1492-1391 (numérique)

Découvrir la revue

Citer ce document

Dilhac, M.-A. (2014). Sélection des ouvrages reçus. Philosophiques, 41(1),

229-230. https://doi.org/10.7202/1025736ar

Ce document est protégé par la loi sur le droit d'auteur. L'utilisation des services d'Érudit (y compris la reproduction) est assujettie à sa politique d'utilisation que vous pouvez consulter en ligne.

https://apropos.erudit.org/fr/usagers/politique-dutilisation/
Cet article est diffusé et préservé par Érudit.

Érudit est un consortium interuniversitaire sans but lucratif composé de l’Université de Montréal, l'Université Laval et l'Université du Québec à Montréal. Il a pour mission la promotion et la valorisation de la recherche. https://www.erudit.org/fr/ 


\section{Sélection des ouvrages reçus}

Althusser, Louis, Initiation à la philosophie pour les non-philosophes, Paris, Presses Universitaires de France, 20I4, 384 p.

Ce texte inédit a été établi et annoté par G. M. Goshgarian et préfacé par Guillaume Sibertin Blanc. Si l'ambition d'Althusser est de rendre accessible la philosophie à plus grand nombre, son initiation à la philosophie n'est pas un essai de vulgarisation, ni un manuel ni même un anti-manuel de philosophie quoiqu'il ait pu inspirer les auteurs de ce nouveau genre philosophique. Althusser esquisse plutôt une histoire de la pensée qui pose d'emblée la question du mode d'existence de la philosophie. Il nous engage dès lors sur le chemin de la philosophie comme réflexion des conditions matérialistes du savoir, comme critique qui ouvre la possibilité d'une action politique.

Belna, Jean-Pierre, Histoire de la logique, Paris, Ellipses, 20I4, $220 \mathrm{p}$.

Comme le titre l'indique clairement, il s'agit d'une histoire de la logique qui expose les principales théories et innovations logiques d'Aristote à Lukasiewicz et Kripke. Cette introduction accessible, rigoureuse et utile met en valeur la pluralité des logiques que la référence à «la » logique oblitère parfois. Du logicien polonais Jan Lukasiewicz, vient de paraître opportunément un recueil de textes édité par S. Richards, F. Shang et K. Vanderborre: Jan Lukasiewicz, Écrits logiques et philosophiques, Paris, Vrin, 2013.

Binoche, Bertrand et Daniel Dumouchel (dir.), Passages par la fiction. Expériences de pensée et autres dispositifs fictionnels de Descartes à Madame de Staël, Paris, Hermann, 2013, 242 p.

Du voile d'ignorance de Rawls à la machine à plaisir de Nozick, du dilemme du tramway fou de Philippa Foot à de la chambre chinoise de Searle, la philosophie contemporaine est saturée d'expériences de pensée, plus ou moins réussies. Pourtant l'usage des fictions en philosophie n'est pas récent et s'il avait déjà cours dans la philosophie ancienne, on peut dire qu'il atteint un apogée aux $17^{\mathrm{e}}$ et $\mathrm{I} 8^{\mathrm{e}}$ siècles. L'ouvrage dirigé par Bertrand Binoche et Daniel Dumouchel explore l'histoire des expériences de pensées à l'époque classique et au siècle des Lumières, expériences de pensée dont une des qualités, aujourd'hui perdue, était la dimension littéraire.

Grangé, Ninon, Carl Schmitt. Nomos, droit et conflit dans les relations internationales, Rennes, Presses Universitaires de Rennes, 20I3, I27 p.

Si les travaux de Carl Schmitt en philosophie politique et en théorie du droit constitutionnel sont à présent bien connus, l'ouvrage dirigé par Ninon Grangé met en valeur la contribution du juriste allemand à la théorie du droit international. Les auteurs reviennent sur les concepts fondamentaux 
schmittiens du théologico-politique, de la souveraineté ou de l'ennemi, pour mieux faire apparaître, sur la toile de la guerre civile mondiale, des motifs hobbesiens que Schmitt déploie de manière originale. On trouvera également la traduction inédite de deux textes: «Le concept de piraterie» et «Sur les deux grands 'dualismes'du système juridique contemporain ».

Jaffro, Laurent (dir.), Croire comme on veut? Histoire d'une controverse, Paris, Vrin, 20I3, 248 p.

Peut-on (et comment peut-on) vouloir croire que Dieu est quand on est un libertin? Cette question qui constitue un des enjeux principaux du pari de Pascal enveloppe une question plus générale, celle de notre contrôle sur nos croyances. Les auteurs de cet ouvrage collectif dirigé par Laurent Jaffro, se proposent de restituer l'histoire d'un débat philosophique de Aristote à Reid en montrant comment ce débat se structure autour des thèses aristotéliciennes et augustiniennes sur la croyance.

Niveleau, Charles-Édouard (dir.), Vers une philosophie scientifique. Le programme de Brentano, Paris, Demopolis, 20I4, 448 p.

Redécouvert dans les années I980, l'inspirateur de la phénoménologie husserlienne fait l'objet d'une impressionnante étude collective de plus de 400 pages, qui couvre son programme de psychologie scientifique. Dirigé par Charles-Édouard Niveleau et préfacé par Jocelyn Benoist, l'ouvrage explore non seulement les contributions proprement brentaniennes à la philosophie de la conscience et de la perception, mais poursuit son enquête chez les disciples, élèves ou héritiers de Brentano: Marty, Meinong, Twardowski et Freud.

Tinland, Franck, Les hommes face au défi de leur humanité. Pour une archéologie de crises annoncées, Hildesheim, Georg Olms Verlag, 2013, 286 p.

Comment penser en temps de crise? Que faire devant de possibles catastrophes? La crise qu'étudie Franck Tinland, c'est celle multiple et globale de l'homme devant sa nature et devant la nature hors de lui, l'environnement. L'auteur, sans catastrophisme mais sans optimisme béat ( «Il ne faut pas rêver ", conclut-il à la page 278), écrit l'histoire longue d'une évolution, celle de l'être humain et de sa relation avec l'environnement, et fait ainsi entrer dans l'histoire humaine l'histoire oubliée de la Terre.

MARC-ANTOINE DILHAC 